Then four walls,

seven windows

reappear. Our shoes

show up, right where we left them, glasses

poised beside the bed, which led us into

such an indistinction: it now pulls apart

into the two of us, meiotic aftermath ...

There is a ticking, there's

a cooling off. Come to my senses, I can see

nine inches from my face

the watched wrists fallen

on a pillow, side by side:

attached to different

beings in time:

one is a bracket of lidded silvers, fast asleep;

the other's open, strapped with hide ...

\title{
The Woman Who Laughed on Calvary
}

Smilers, grinners,

smirkers, spinners

of wishes for nice

and nicer days: I didn't

laugh like you, who live for mere

amusement. The truth is

laughter's not

a mark of pleasure,

either intended or ex-,

no simple pleasantry outspread

or, smiling, rent: instead

it is the sign of a delirium,

spilt brain upon split

lip, an uncontainable

interiority- 
(make no mistake, the interior is horror: your own deepest intimate is there, made of redder smear and whiter seepages than any mouthpiece now can tell-at first only the most ephemeral offal and then the least and then (not least, beneath) the lasting stones and struts, insensate, to which yea these many centuries the hope of slime has always loved adhering . . . Your interior life! Your pet pretense! It can't be kept up, kept clean even, even in a thought, except a good bloodworks or shitpump keeps it so.) Out of the mouth comes nothing decorous

but words, and even words can't save the fiction. All our belches, cries, upchucks and sneezes, puffings, hiccups, kissing sounds and coughs are laughter: get it straight: a laugh is nothing smiled or mild or meanwhiling - a laugh's got teeth in it, immediate, and spit; for grimace is its closest kin, a grimacing with wind.

It issues always from an inadvertency, it bursts out, will be damned - a vent of rage or irony right in the shrine of signs . . . I call it laughter: voice of expiration, sorrow's very archery 
and signature: the hoist of flesh arrayed on roost of skeleton. The common wisdom is I laughed in heartlessness or mockery: perhaps I didbut at the long and short of it, what good comes to, the soft and hard, the awful fact that what's alive will rot, what lasts can't feel. I felt

how terrible a figure human being cuts, upon its frame.

And so the laugh like a cry from my own perscrewed, misnailed, cross-crafted armature rang out, outrang the meeker mourners and polite conventioneers ... The heart

is a muscle. The tooth is a fang. What I gave at the sight of him there was up. What I got of humanity there was the hang...

\section{Connubial}

Dream is matterless, it dips from bounds to billowings,

laws lapse in it, or universes swerve.

Before I had an other at my side there was no side: how far can onesome go? Just being 